\title{
Qi-Shen-Yi-Qi Dripping Pills Promote Angiogenesis of Ischemic Cardiac Microvascular Endothelial Cells by Regulating MicroRNA-223-3p Expression
}

\author{
Guo-Hua Dai, ${ }^{1}$ Ning Liu, ${ }^{2}$ Jing-Wei Zhu, ${ }^{3}$ Jing Yao, ${ }^{3}$ Chun Yang, \\ Pei-Ze Ma, ${ }^{4}$ and Xian-Bo Song ${ }^{2}$ \\ ${ }^{1}$ Department of Cardiology, Affiliated Hospital of Shandong University of Traditional Chinese Medicine, Jinan 250011, China \\ ${ }^{2}$ Department of Cardiology, Jining Hospital of Traditional Chinese Medicine, Jining 272000, China \\ ${ }^{3}$ Shandong University of Traditional Chinese Medicine, Jinan 250014, China \\ ${ }^{4}$ Department of Cardiology and Brain, Weihai Hospital of Traditional Chinese Medicine, Weihai 264200, China \\ Correspondence should be addressed to Guo-Hua Dai; daigh2015@163.com
}

Received 30 July 2015; Revised 10 November 2015; Accepted 1 December 2015

Academic Editor: Shun-Wan Chan

Copyright (C) 2016 Guo-Hua Dai et al. This is an open access article distributed under the Creative Commons Attribution License, which permits unrestricted use, distribution, and reproduction in any medium, provided the original work is properly cited.

\begin{abstract}
Traditional Chinese medicine (TCM) research shows that Qi-Shen-Yi-Qi Dripping Pills (QSYQ) can promote ischemic cardiac angiogenesis. Studies have shown that microRNAs (miRNAs) are the key component of gene regulation networks, which play a vital role in angiogenesis and cardiovascular disease. Mechanisms involving miRNA by which TCM promotes ischemic cardiac angiogenesis have not been reported. We found that microRNA-223-3p (mir-223-3p) was the core miRNA of angiogenesis of rats ischemic cardiac microvascular endothelial cells (CMECs) and inhibited angiogenesis by affecting RPS6KB1/HIF-1 $\alpha$ signal pathway in previous study. Based on the results, we observed biological characteristics and optimal dosage for QSYQ intervening in rats ischemic CMECs angiogenesis and concluded that QSYQ low-dose group had the strongest ability to promote angiogenesis of ischemic myocardium. Using miRNA chip and real-time PCR techniques in this study, we identified mir-223-3p as the pivotal miRNA in QSYQ that regulated angiogenesis of ischemic CMECs. From real-time PCR and western blot analysis, research showed that gene and protein expression of factors located RPS6KB1/HIF-1 $\alpha$ signaling pathway, including HIF-1 $\alpha$, VEGF, MAPK, PI3K, and AKT, were significantly upregulated by QSYQ to regulate angiogenesis of ischemic CMECs. This study showed that QSYQ promote ischemic cardiac angiogenesis by downregulating mir-223-3p expression in rats ischemic CMECs.
\end{abstract}

\section{Introduction}

Ischemic heart disease is a common clinical condition with a high incidence rate. Currently, ischemic heart disease has been studied widely both in China and overseas in terms of means to promote ischemic cardiac angiogenesis. According to research in traditional Chinese medicine (TCM), the main causes for ischemic heart disease are a deficiency of Qi and clotting of blood vessels; therefore, TCM recommends Qi-replenishing and blood-activating therapy for treatment. "Qi-replenishing" is a method of nourishing vital essence, applying to shortness of breath, pale complexion, tired spirit, lassitude of limb, and other symptoms. Ancient Chinese literature has long recorded Qi-replenishing and bloodactivating theories including "vasculogenesis" and "blood generating," which are closely related to angiogenesis [1]. QiShen-Yi-Qi Dripping Pills (QSYQ), comprising herbs such as Astragalus, red sage, Panax notoginseng, and Dalbergia odorifera, help replenish Qi, clear blood clots, activate blood flow, relieve pain, and are representative of Qi-replenishing and blood-activating TCM used to treat ischemic heart disease. MicroRNAs (miRNAs) are key regulators of gene expression, mainly via negative regulation, inhibiting target mRNA translation or inducing degradation of mRNA [2]. Thus, miRNAs play an important role in angiogenesis and cardiovascular disease. QSYQ can promote ischemic cardiac 
angiogenesis, but their mechanism of modulating ischemic cardiac angiogenesis by regulating miRNA expression has not been reported in detail.

In the previous study [3], we found that microRNA223-3p (mir-223-3p) was the core miRNA of angiogenesis of rats ischemic cardiac microvascular endothelial cells (CMECs), which targeted Rps6kbl and inhibited angiogenesis of ischemic myocardium via regulating RPS6KB1/HIF-1 $\alpha$ signal pathway. On the base, we focused on the biological characteristics and optimal dosage for QSYQ promoting rats ischemic CMECs angiogenesis. We utilized miRNA chips and real-time polymerase chain reaction (real-time PCR) techniques in this study, to analyze the mechanism through which QSYQ modulated angiogenesis by CMECs by regulating miRNA expression. It is concluded that QSYQ can downregulate mir-223-3p expression, activate RPS6KB1/HIF- $\alpha$ signaling pathway, and promote ischemic cardiac angiogenesis.

\section{Materials and Methods}

2.1. Animal Gavage and Preparation of TCM-Containing Serum. This study was approved by the Committee of Ethics regarding Experimental Animals in Shandong Lukang Pharmaceutical Co., Ltd. A total of 20 male, Sprague Dawley rats ( $220 \mathrm{~g}$ to $280 \mathrm{~g}$ ) were purchased from Animal Experiment Center of Shandong Lukang Pharmaceutical Co., Ltd., and randomly assigned to 4 groups: QSYQ high-dose group (Q$\mathrm{H})$, and $70 \mathrm{mg} /(\mathrm{kg} \cdot \mathrm{d})$ was administered to it; QSYQ mediumdose group (Q-M), and $35 \mathrm{mg} /(\mathrm{kg} \cdot \mathrm{d})$ was administered to it; QSYQ low-dose group (Q-L), and $17.5 \mathrm{mg} /(\mathrm{kg} \cdot \mathrm{d})$ was administered to it; and blank serum group, and the same volume of distilled water was administered to it. Each group contained 5 rats and treatment was administered to each rat by oral gavage at $4 \mathrm{~mL} /$ treatment/day, for 5 days consecutively. An hour after the last gavage, serum was collected from the aorta abdominalis and prepared as per the method described below [4]. The rats were anesthetized via intraperitoneal injection of $10 \%$ chloral hydrate $(0.3 \mathrm{~mL} / 100 \mathrm{~g})$, with limbs fixed and sterilized. Abdominal cavity was opened by a sterilized surgery scissor and the aorta abdominalis was isolated. A $0.2 \mathrm{~mm}$ gauge needle was inserted into the aorta abdominalis facing the direction of blood flow and blood was collected in a tube without anticoagulant. Rats were euthanized by overdose anesthesia with $10 \%$ chloral hydrate $(0.6 \mathrm{~mL} / 100 \mathrm{~g})$ after harvesting 6-8 mL blood in the experiment. Blood was centrifuged for $15 \mathrm{~min}$ at $3000 \mathrm{rpm}$, serum was separated in a sterile environment, filtered through a $0.22 \mu \mathrm{m}$ microporous film, and aliquots were prepared, sealed, and stored at $-20^{\circ} \mathrm{C}$.

2.2. Rat Myocardial Infarction Model and Cell Culture. A model for myocardial infarction in rat was prepared as previously described [3], using the ligature method [5]. The ligature was considered successful when the postsurgery electrocardiogram showed Q wave and ST wave elevated as well as $\mathrm{T}$ wave elevated or upside down. Animals that survived for $24 \mathrm{~h}$ after surgery showed the success of the model. CMECs were cultured as previously described [3] using the explant culture method [6]. When a large number of cells surrounded the tissue, it was removed, medium was replenished every 2 days, and cells were cultured until there is almost fusion between the growing cells. Previous studies have shown that cells cultured in this way were CMECs [7].

2.3. Experimental Groups. Rat ischemic CMECs were randomly assigned into 4 groups: Q-H, Q-M, Q-L, and ischemia model (M). Normal rat-originated passage-zero CMECs (N) were used as control group. Thus, 5 groups were assigned in total. When cells have grown until near fusion, they were digested by $0.25 \%$ Trypsin-EDTA, suspended in cell culture medium with $10 \%$ TCM-containing serum (Q-H, Q-M, and $\mathrm{Q}-\mathrm{L}$ groups) or blank serum ( $\mathrm{M}$ and $\mathrm{N}$ groups).

2.4. Cell Proliferation. Trypan blue colorimetric assay was used to measure cell proliferation [8-11]. Cell suspension was seeded into a 96 -well plate at $4 \times 10^{3}$ cells/well, 6 wells/group, and 1 control well (with the same volume of cell-free medium added). Cells were cultured routinely for 7 days and 6 wells were used for colorimetry each day. For the colorimetry assay, $20 \mu \mathrm{L}$ of MTT solution $(5 \mathrm{mg} / \mathrm{mL})$ was added to each well and incubated at $37^{\circ} \mathrm{C}$ for $4 \mathrm{~h}$. Culture supernatant was dispensed into fresh wells, $150 \mu \mathrm{L}$ of dimethyl sulfoxide was added, shaken well for $10 \mathrm{~min}$, and absorption was measured at $490 \mathrm{~nm}$ using an enzyme-linked immunosorbent assay reader. Proliferation rate and proliferation window period were calculated. The growth curve was plotted for time on the horizontal axis and absorption value on the vertical axis.

2.5. Cell Migration. Cell migration was measured by woundhealing experiments [12]. Cell suspension solution was seeded in a 24 -well plate at $5 \times 10^{4}$ cells/well. After the cells are attached, a "wound" was created by marking a "+" sign in the center at the bottom of each well using a sterile $10 \mu \mathrm{L}$ tip and the wound-healing capacity of cells was monitored after $0,6,12,24,48$, and $72 \mathrm{~h}$ using an inverted microscope $(50 \mathrm{x})$, images were captured, and cells that had migrated were counted. A total of 3 samples were taken from each group, in triplicate. Migration percentage and migration window period were calculated.

2.6. Tube Structure Formation. CMEC tube structure formation was studied as previously described $[13,14]$ and the number of tubes formed was counted. Cell suspension was seeded into 6 -well plates at $5 \times 10^{4}$ cells/well, 6 wells/group, and tube formation was monitored under an inverted microscope (100x) after 24, 48, 72, and 96 hours. Tube formation was considered positive if the endothelial cells interconnected, forming a C-shape. Within each well, 3 areas of intensive tube formation were selected, and tubes were counted. A total of 10 images were randomly collected from each group and used to calculate the tube formation percentage and tube forming window period.

2.7. miRNA Gene Chip Analysis. As per the window period characteristics of ischemic CMEC angiogenesis in each group, the optimal dosage and window period were selected as the intervention group. Total RNA was collected from 
the cells in the intervention, $\mathrm{M}$, and $\mathrm{N}$ groups. The ratio of $\mathrm{OD}_{260 \mathrm{~nm}} / \mathrm{OD}_{280 \mathrm{~nm}}$ was measured by ultraviolet-visible spectroscopy and total RNA content was determined by formaldehyde-denatured agarose electrophoresis. miRNA was marked and the sample was concentrated with miRCURYTM Array Power Labeling kit and Rneasy mini kit assays. The miRNA chip was hybridized with miRCURYTM Array microarray kit and Hybridization Chamber II assays. Images were scanned using Genepix 4000B and data collected was analyzed using Genepix Pro 6.0 software. Based on gene expression content, differences at $\geq$ twice the gene expression were used as standard and $\mathrm{N}$ group was used as control, differentially expressed miRNAs from the intervention and $\mathrm{M}$ groups were selected, including miRNAs that were upregulated or downregulated $\geq 2$ times, and miRNAs with significantly different expression were selected. These miRNAs were then compared with those with significantly different expression in the intervention and $M$ groups and the core miRNA in QSYQ regulating ischemic CMECs was identified. Chip hybridization and data analysis were conducted at Shanghai Kangcheng Bioengineering Co., Ltd.

2.8. Confirming Core miRNA with Real-Time PCR. Realtime PCR was used to test the expression of core miRNA in different groups of cells. Total RNA was extracted from samples in each group and RNA concentration and purity were measured by ultraviolet-visible spectroscopy. RNA was reverse-transcribed to cDNA following reverse-transcription kit assay instructions. Real-time PCR with all cDNA samples was run as follows: $95^{\circ} \mathrm{C}$ for $5 \mathrm{~min} ; 95^{\circ} \mathrm{C}$ for $10 \mathrm{~s}, 60^{\circ} \mathrm{C}$ for $10 \mathrm{~s}$, and $72^{\circ} \mathrm{C}$ for $10 \mathrm{~s}$, for 45 cycles; $95^{\circ} \mathrm{C}$ for $5 \mathrm{~s}, 60^{\circ} \mathrm{C}$ for $1 \mathrm{~min}$, $97^{\circ} \mathrm{C}$ for $5 \mathrm{~s}$, and $40^{\circ} \mathrm{C}$ for $30 \mathrm{~s}$. Data was analyzed by using $2^{-\Delta \Delta \mathrm{Ct}}$ method.

2.9. Analysis of mRNA Expression of Related Genes in the RPS6KB1/HIF-1 $\alpha$ Signaling Pathway Using Real-Time PCR. Real-time PCR was used to test mRNA expression of Rps $6 \mathrm{kbl}$, HIF-1 $\alpha$, VEGF, MAPK, PI3K, and AKT in each group (intervention group, $\mathrm{M}$ group, and $\mathrm{N}$ group).

2.10. Western-Blot Analysis. Total protein was extracted from samples in each group using a total protein extraction reagent and protein concentration was estimated using BCA method. Sample solution and prestained protein markers were loaded and proteins were separated by electrophoresis. A stack of filter paper, gel, and cellulose was prepared as per Bio-Rad protein transfer unit instructions, and proteins were transferred to the cellulose membrane, blocked for $1 \mathrm{~h}$ in $5 \%$ fatfree milk at room temperature. Primary antibody was added to the blocked film, so that antigen and antibody combined and incubated overnight at $4^{\circ} \mathrm{C}$ and then secondary antibody with HRP marker was added. Meanwhile $\beta$-actin antibody with HRP marker was used to test $\beta$-actin content. The substrate was added, after which the film combined and reacted with the chemiluminescent substrate, and images were captured, scanned, and analyzed to calculate the sample density with densitometry. Density of target protein divided by density of inner control $\beta$-actin, to adjust for standard error, was calculated, and the relative content of target protein in the sample was obtained.

2.11. Statistical Analysis. The data was presented as mean \pm standard deviation. Statistical comparisons were performed using one-way analysis of variance and independent sample $t$-test after one-way ANOVA. $P<0.05$ was considered statistically significant.

\section{Results}

3.1. Rat Myocardial Infarction Model Building and Cell Culture. This study had used 54 rats finally, and there were two rats that failed in respiration and circulation in 24 hours after mice model establishment. After the rat's left anterior descending coronary artery (LAD) was ligated, electrocardiograms indicated that ST segment elevated significantly (Figure 1(a)), which proved that the built model was successful. Immunocytochemical stain revealed that VIII factor and CD31 expressed positively in cells (Figure 1(b)), which proved that the cultured cells were CMECs.

3.2. Growth Curve and Proliferation Rate of Ischemic CMECs. Latent periods during growth were observed for CMECs in each group. Rapid growth was noted on the 2nd day in Q-L and Q-M groups, compared to the 3rd day in the Q$\mathrm{H}$ and $\mathrm{N}$ groups, after which a plateau was observed. $\mathrm{M}$ group showed rapid growth on the 6th day and did not show any obvious plateau (Figure 2(a)). Proliferation rate for the QSYQ-treated groups was higher than that for the M group, while proliferation rate of Q-L group was significantly higher than that of Q-M group $(P<0.01$, Figure $2(\mathrm{~b}))$. The window period of proliferation was found for cells within each group via active monitoring (Table 1).

3.3. Ischemic CMEC Migration and Tube Structure Formation. Compared with $\mathrm{M}$ group, significantly more cells migrated in the QSYQ-treated group (Figure 3(a)); the migration rate of Q-L group at 12 hours was significantly higher than that of other groups $(P<0.01$, Figure 3(b)); the migration window period in each group was found via active monitoring (Table 1). Compared with $\mathrm{M}$ group, the tube formation numbers in QSYQ-treated groups were significantly higher (Figure 4(a)); tube formation rate of Q-L group on the 2nd day was significantly higher than that of other groups $(P<$ 0.01 , Figure 4(b)); the cell tube formation window period of each group was found via active monitoring (Table 1).

3.4. QSYQ Regulate miRNAs Expression during Ischemic CMECs Angiogenesis. There has been no previous report on the target and mechanism of regulation miRNA expression by QSYQ on ischemic CMECs angiogenesis. In this study, we used miRNA chip and real-time PCR techniques to analyze the optimum QSYQ dose for regulation of miRNA expression during ischemic CMEC angiogenesis. Compared with $\mathrm{N}$ group, there were 8 upregulated and 15 downregulated miRNAs in M group (Table 2) and 16 upregulated and 18 downregulated miRNAs in Q-L group (Table 2). Compared with $\mathrm{M}$ group, there were 26 upregulated miRNAs and 21 

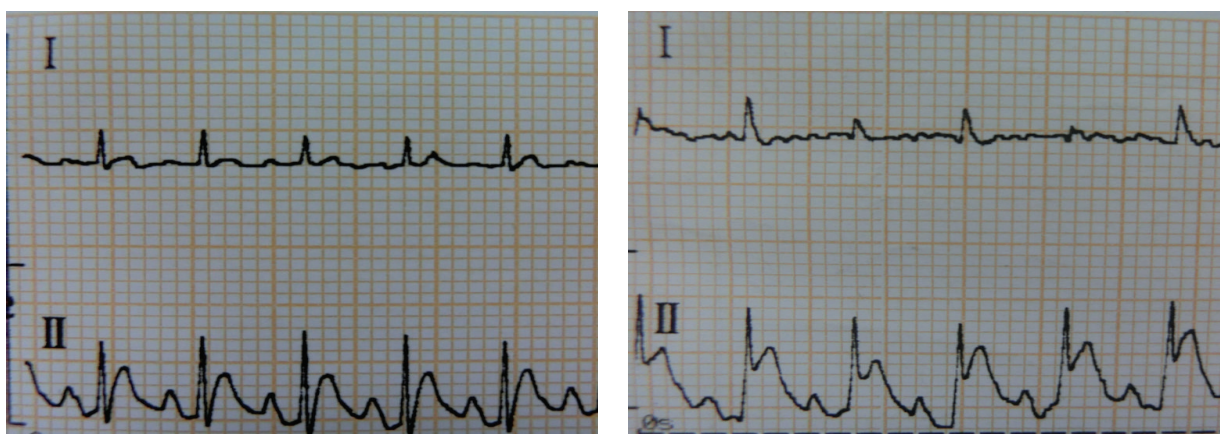

(a)
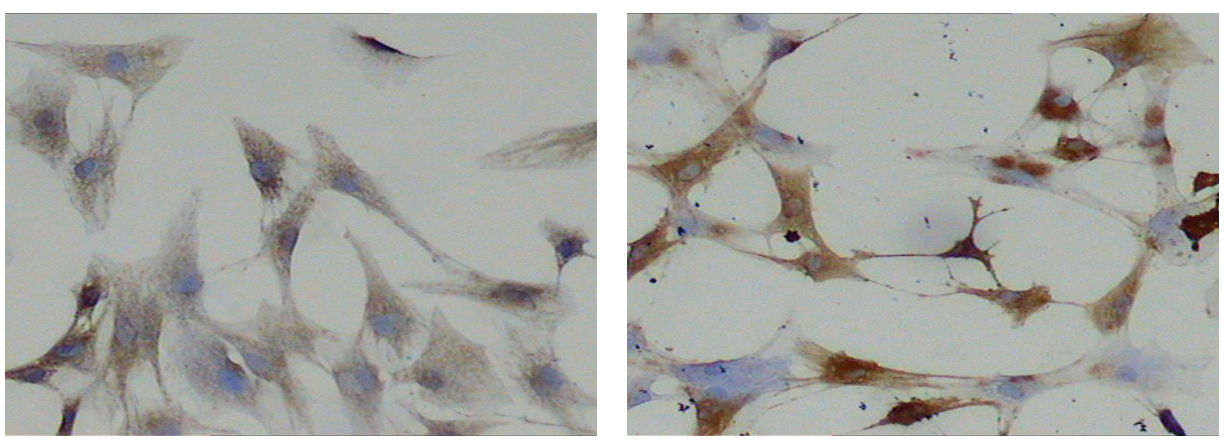

(b)

FIGURE 1: (a) left: a normal electrocardiogram of rat before the model building. (a) right: after the model building, electrocardiograms showed II indicated ST segment elevated significantly, which indicated ischemia myocardial and proved that the artery ligation was successful. (b) Immunocytochemical stain revealed that, after the staining of VIII factor (left), the cytoplasm was brown coloring and the coloring was the most significant in pericaryon and, after the staining of CD31 (right), their cell membrane showed yellowish brown particles, which proved that the cultured cells were CMECs.

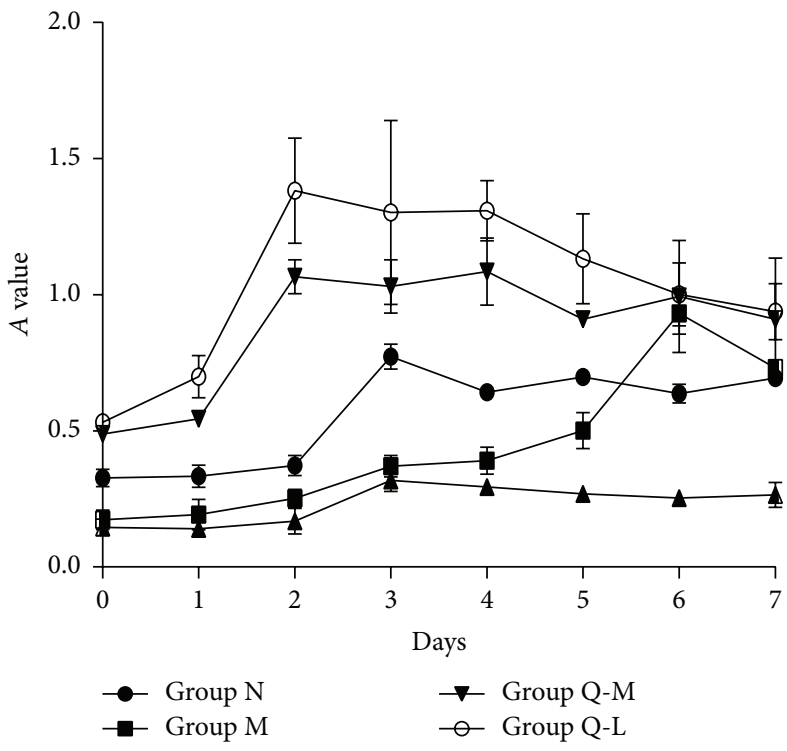

(a)

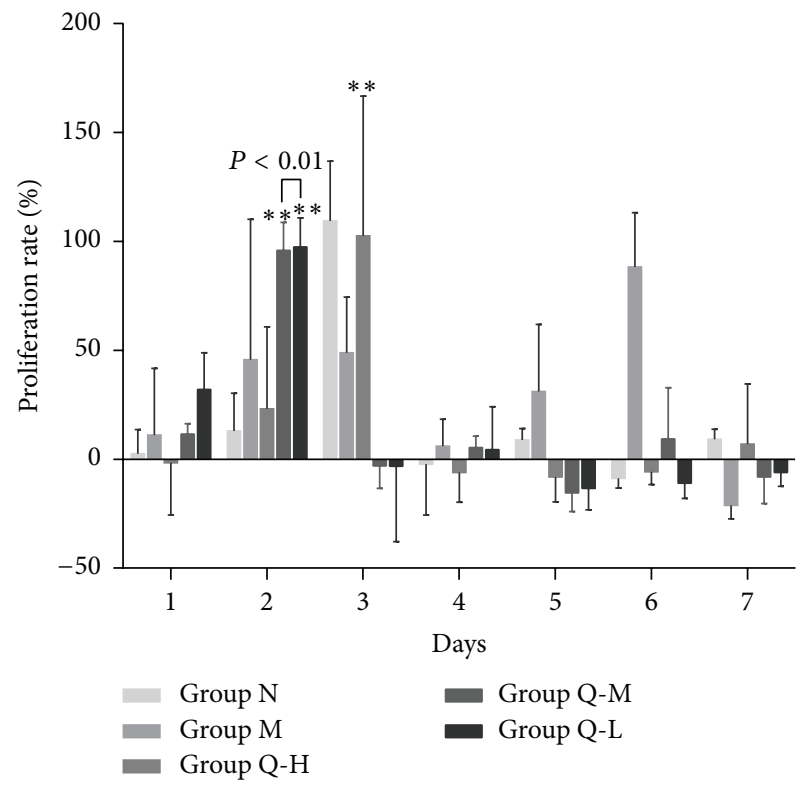

(b)

Figure 2: (a) The OD value of ischemic CMECs in Q-L group was significantly higher than that of other groups. Ischemic CMECs in Q-L group and Q-M group proliferated vigorously on the second day, while $\mathrm{M}$ group was on the sixth day. (b) A dynamic observation revealed that proliferation rate for all the three QSYQ-treated groups was higher than that of the M group $\left({ }^{* *} P<0.01\right)$. The proliferation window period of ischemic CMECs in Q-L group and Q-M group was four days ahead of the M group. 

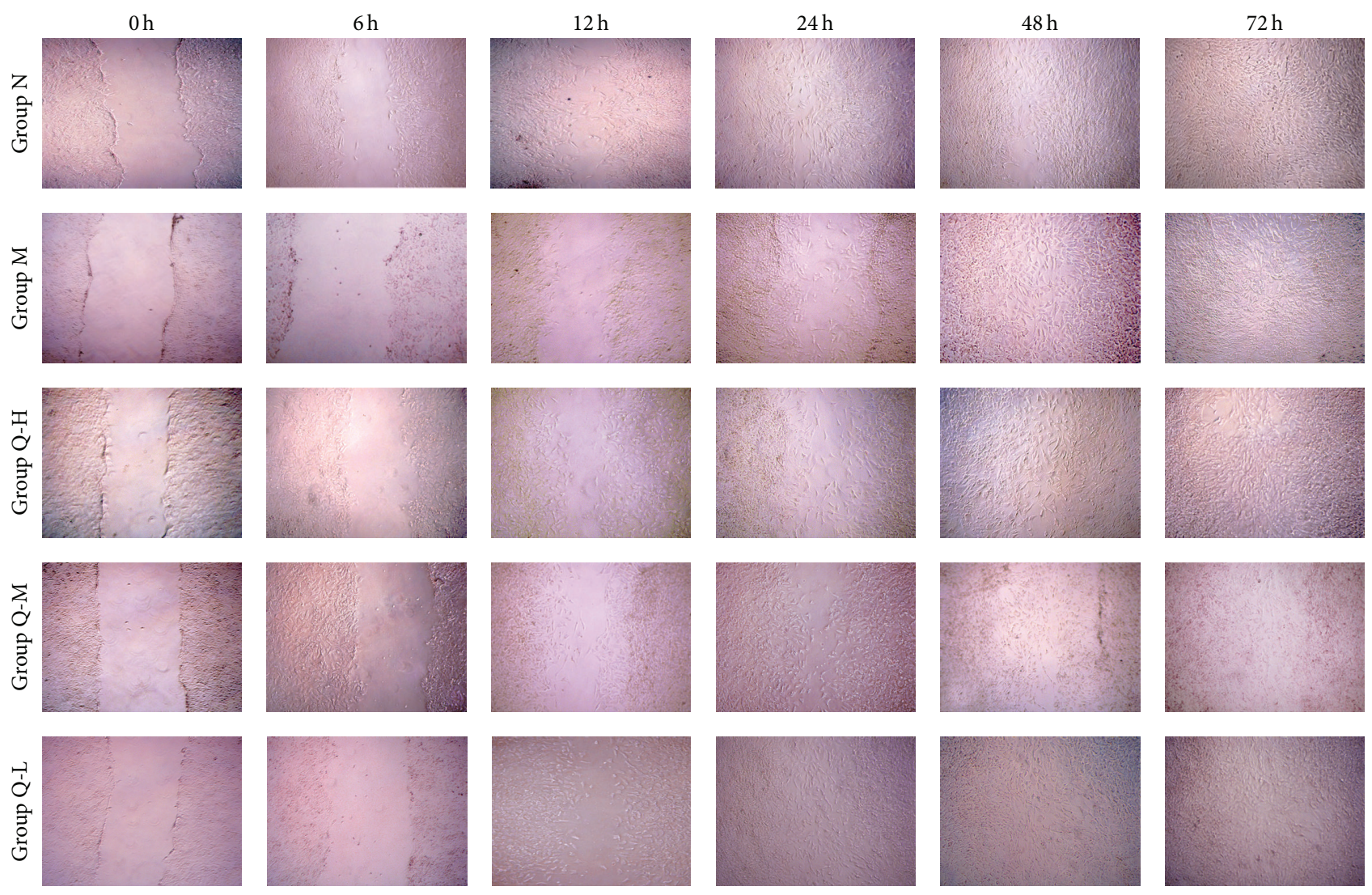

(a)

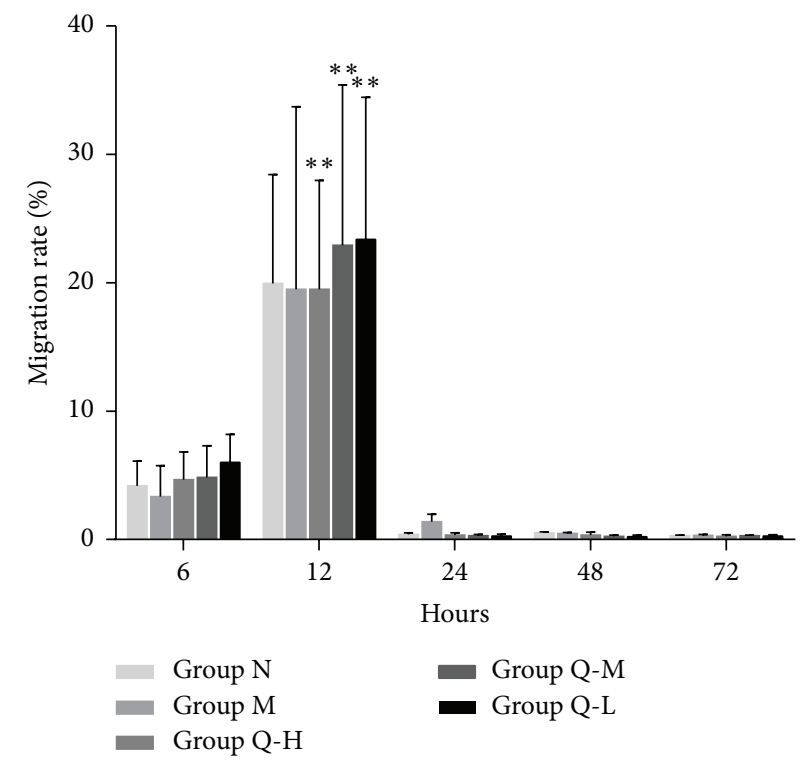

(b)

FIGURE 3: (a) For all groups, a clear scratching blank area could be spotted after scratching test zero hour under microscope (50x), while the blank area was covered extensively with the large amount of cells after twelve hours. The numbers of migrated cells in the QSYQ-treated groups were more than that in M group at the same timescale. (b) A dynamic observation revealed that migration rate of all the three QSYQ-treated groups increased significantly compared with that for the $\mathrm{M}$ group $\left({ }^{* *} P<0.01\right)$, especially Q-L group. 
TABLE 1: The window phases of proliferation, migration, and tube formation of the five groups.

\begin{tabular}{llccc}
\hline Group & \multicolumn{1}{c}{$\mathrm{N}$} & $\mathrm{M}$ & $\mathrm{Q}-\mathrm{H}$ & Q-M \\
\hline Proliferation & The third day & The sixth day & The third day & The second day \\
$\begin{array}{l}\text { Migration } \\
\text { Tube formation }\end{array}$ & Half of a day & Half of a day & Half of a day & Half of a day second day \\
\hline
\end{tabular}
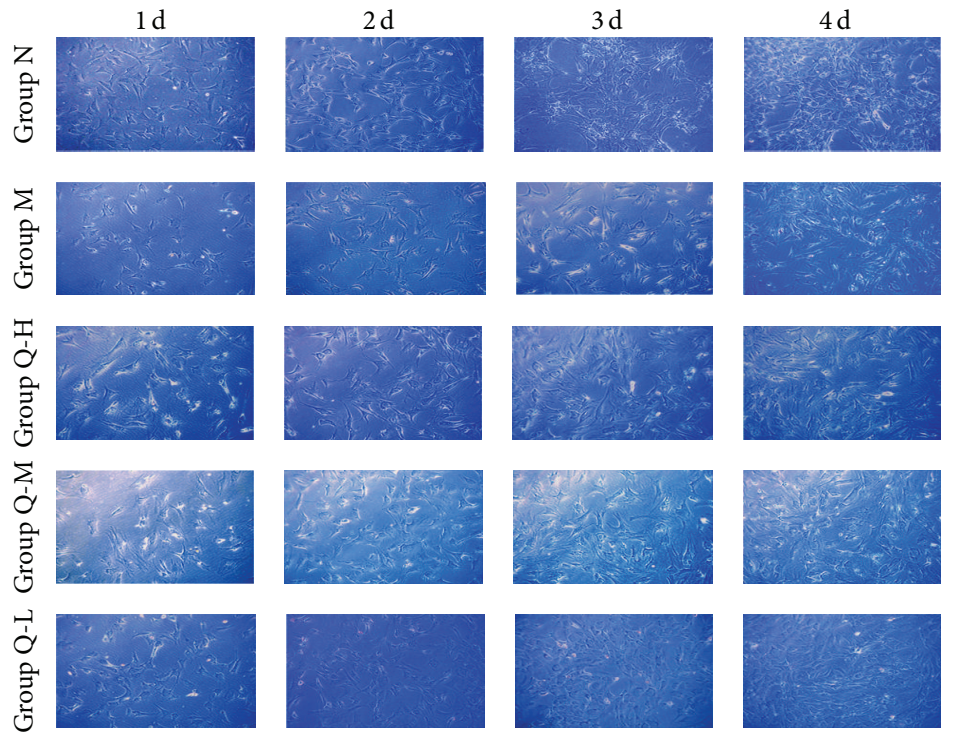

(a)

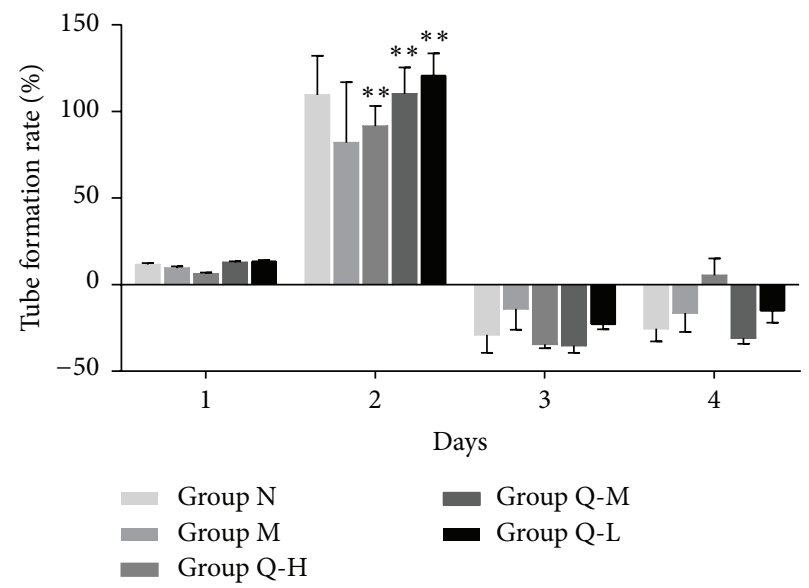

(b)

FIGURE 4: (a) For all groups, observation under inverted phase contrast microscope (100x) revealed that amounts of "C" shaped tube formation were formed significantly on the second day. The "C" shaped tube structure decreased gradually on the third day and the fourth day with increased cell numbers. The tube formation counts for the QSYQ-treated groups were more than that for the M group at the same timescale. (b) A dynamic observation revealed that tube formation rate of all the three QSYQ-treated groups increased significantly compared with that for the M group $\left({ }^{* *} P<0.01\right)$, especially Q-L group.

downregulated miRNAs in Q-L group (Table 2). Considering the link between differences in miRNA expression and angiogenesis, mir-223-3p was identified as the key miRNA during the proliferation period in the Q-L group. Compared with M group, the expression of mir-223-3p was downregulated 0.117 times in Q-L group, which showed a significant expression difference $(P<0.01)$. Thus, we concluded that mir-223$3 p$ was the core miRNA for regulating ischemic CMECs angiogenesis by QSYQ. The miRNA expression heat map is presented in Figure 5(a).

Real-time PCR was used to verify the results from miRNA chip experiments on mir-223-3p expression and the results were found to be consistent. Compared with $\mathrm{N}$ group, there was significant upregulation of mir-223-3p expression in $\mathrm{M}$ group $(P<0.01)$ and downregulation in $\mathrm{Q}-\mathrm{L}$ group $(P<0.05)$; compared with $M$ group, there was significant 


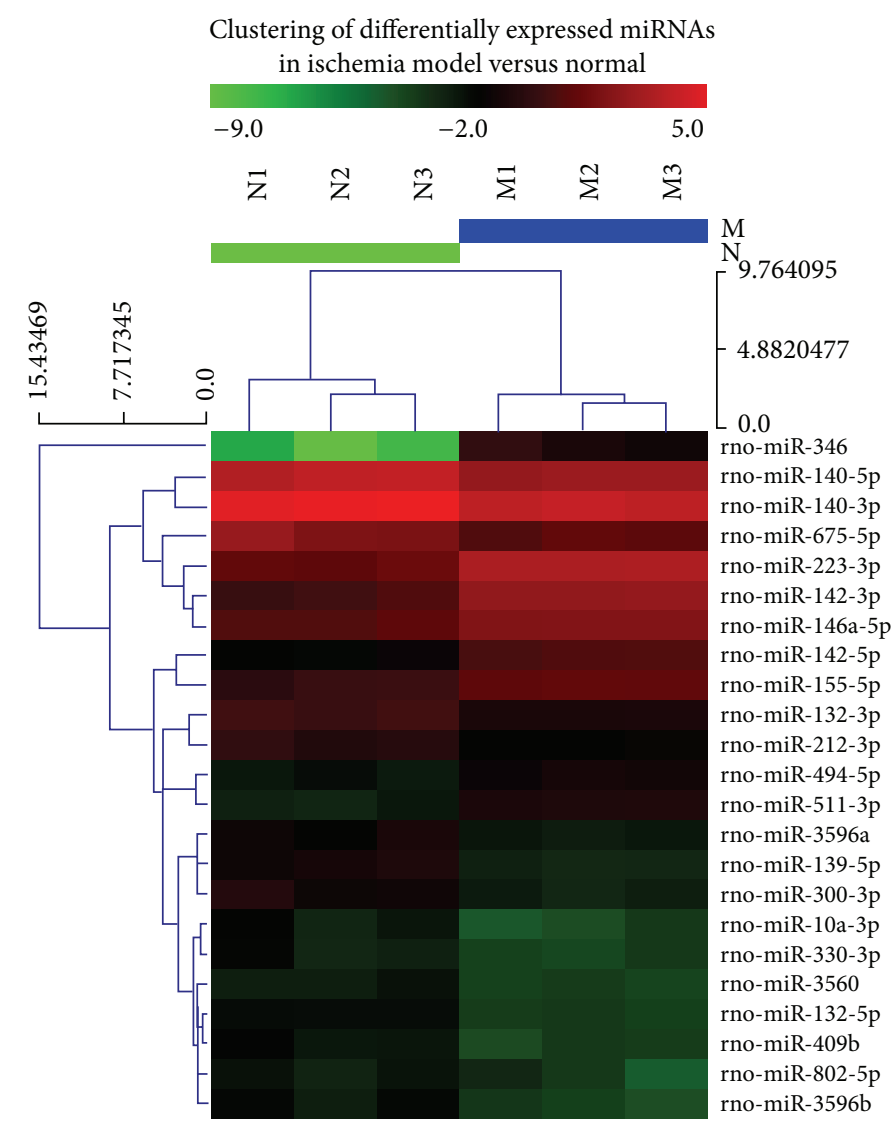

Clustering of differentially expressed miRNAs in QSYQ low-dose versus normal

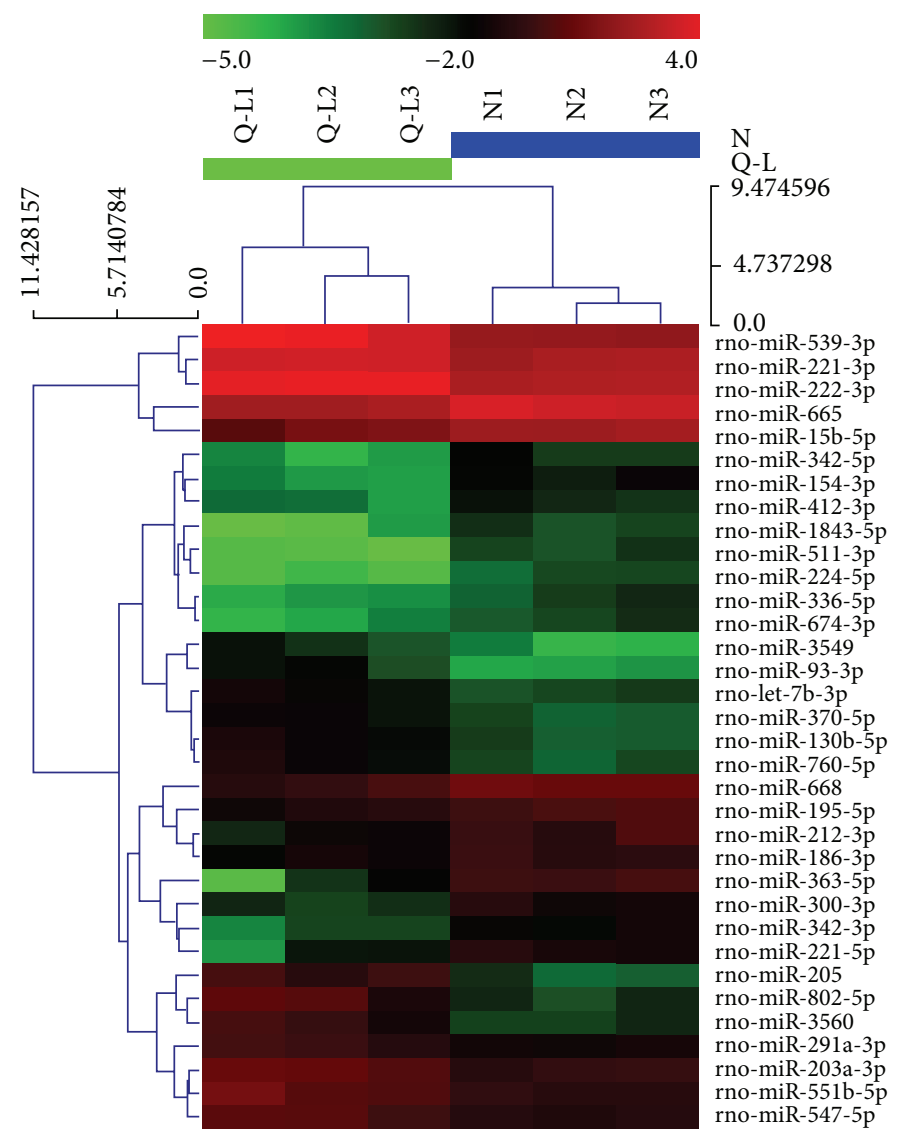

FIgure 5: Continued. 


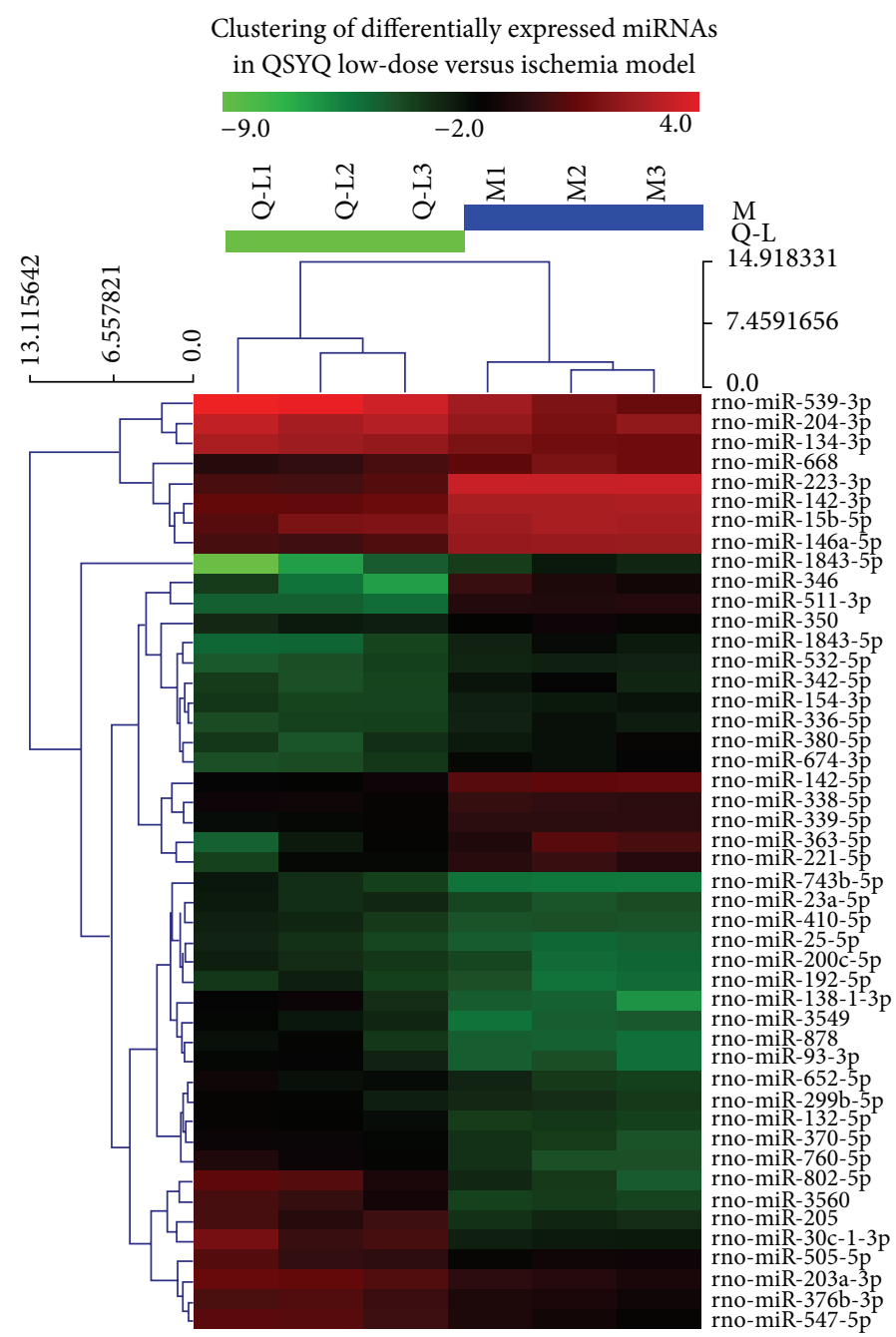

(a)

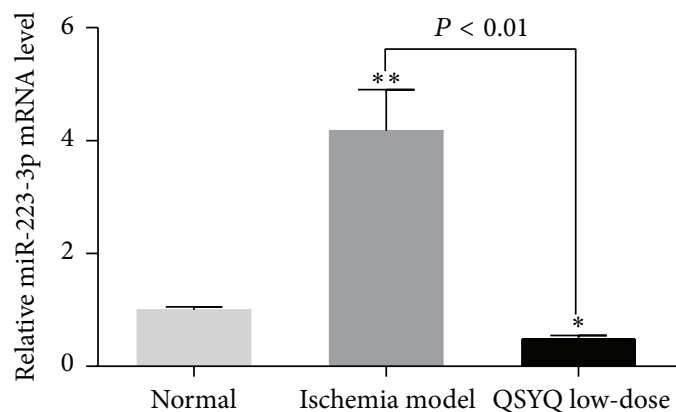

(b)

FIGURE 5: (a) The heat map diagram displayed the results of the two-way hierarchical clustering of miRNAs and samples. Each row represented a miRNA and each column stood for a sample. The miRNA clustering tree was displayed on the left, and the sample clustering tree appeared at the top. Cluster analysis arranged samples and miRNAs into groups based on their expression levels. Red indicated highly relative expression, and green indicated low relative expression. (b) The results of microarray assay of mir-223-3p were confirmed by real-time PCR in the same set of samples. $\Delta \mathrm{Ct}$ values were normalized to U6 levels. The results were expressed as $2^{-\Delta \Delta \mathrm{Ct}}$. ${ }^{*} P<0.05,{ }^{* *} P<0.01$. 
TABLE 2: The differential expression of miRNAs in ischemia model group, QSYQ low-dose group, and normal group.

\begin{tabular}{|c|c|c|c|c|c|}
\hline Gene & Fold change & $P$ value & Gene & Fold change & $P$ value \\
\hline \multicolumn{6}{|c|}{ Upregulated miRNAs in ischemia model versus normal group } \\
\hline rno-miR-346 & 96.774 & 0.014 & rno-miR-511-3p & 3.294 & 0.000 \\
\hline rno-miR-142-5p & 4.741 & 0.000 & rno-miR-146a-5p & 2.395 & 0.000 \\
\hline rno-miR-142-3p & 4.533 & 0.000 & rno-miR-155-5p & 2.171 & 0.000 \\
\hline rno-miR-223-3p & 4.299 & 0.000 & rno-miR-494-5p & 2.056 & 0.002 \\
\hline \multicolumn{6}{|c|}{ Downregulated miRNAs in ischemia model versus normal group } \\
\hline rno-miR-3596a & 0.490 & 0.028 & rno-miR-675-5p & 0.415 & 0.042 \\
\hline rno-miR-802-5p & 0.486 & 0.040 & rno-miR-132-5p & 0.392 & 0.000 \\
\hline rno-miR-140-5p & 0.480 & 0.005 & rno-miR-409b & 0.383 & 0.008 \\
\hline rno-miR-132-3p & 0.460 & 0.000 & rno-miR-3596b & 0.372 & 0.008 \\
\hline rno-miR-3560 & 0.447 & 0.004 & rno-miR-300-3p & 0.340 & 0.017 \\
\hline rno-miR-140-3p & 0.440 & 0.001 & rno-miR-10a-3p & 0.337 & 0.035 \\
\hline rno-miR-330-3p & 0.440 & 0.049 & rno-miR-139-5p & 0.312 & 0.003 \\
\hline rno-miR-212-3p & 0.429 & 0.005 & & & \\
\hline \multicolumn{6}{|c|}{ Upregulated miRNAs in QSYQ low-dose versus normal group } \\
\hline rno-miR-205 & 5.660 & 0.005 & rno-miR-130b-5p & 2.498 & 0.031 \\
\hline rno-miR-802-5p & 5.562 & 0.043 & rno-miR-551b-5p & 2.279 & 0.048 \\
\hline rno-miR-539-3p & 4.205 & 0.012 & rno-miR-370-5p & 2.198 & 0.006 \\
\hline rno-miR-3560 & 4.052 & 0.035 & rno-miR-547-5p & 2.156 & 0.013 \\
\hline rno-miR-93-3p & 3.020 & 0.016 & rno-miR-203a-3p & 2.135 & 0.009 \\
\hline rno-miR-3549 & 2.656 & 0.025 & rno-miR-291a-3p & 2.039 & 0.030 \\
\hline rno-miR-222-3p & 2.538 & 0.000 & rno-let-7b-3p & 2.034 & 0.024 \\
\hline rno-miR-760-5p & 2.509 & 0.042 & rno-miR-221-3p & 2.008 & 0.000 \\
\hline \multicolumn{6}{|c|}{ Downregulated miRNAs in QSYQ low-dose versus normal group } \\
\hline rno-miR-186-3p & 0.490 & 0.016 & rno-miR-668 & 0.434 & 0.002 \\
\hline rno-miR-195-5p & 0.484 & 0.007 & rno-miR-300-3p & 0.404 & 0.024 \\
\hline rno-miR-412-3p & 0.471 & 0.008 & rno-miR-221-5p & 0.388 & 0.021 \\
\hline rno-miR-665 & 0.463 & 0.002 & rno-miR-342-5p & 0.371 & 0.038 \\
\hline rno-miR-336-5p & 0.460 & 0.020 & rno-miR-224-5p & 0.340 & 0.003 \\
\hline rno-miR-674-3p & 0.458 & 0.015 & rno-miR-1843-5p & 0.310 & 0.004 \\
\hline rno-miR-15b-5p & 0.457 & 0.006 & rno-miR-154-3p & 0.303 & 0.003 \\
\hline rno-miR-342-3p & 0.441 & 0.006 & rno-miR-511-3p & 0.254 & 0.001 \\
\hline rno-miR-212-3p & 0.440 & 0.011 & rno-miR-363-5p & 0.192 & 0.001 \\
\hline \multicolumn{6}{|c|}{ Upregulated miRNAs in QSYQ low-dose versus ischemia model group } \\
\hline rno-miR-802-5p & 11.437 & 0.031 & rno-miR-547-5p & 2.944 & 0.007 \\
\hline rno-miR-3560 & 9.074 & 0.020 & rno-miR-192-5p & 2.760 & 0.049 \\
\hline rno-miR-30c-1-3p & 7.638 & 0.049 & rno-miR-203a-3p & 2.718 & 0.005 \\
\hline rno-miR-138-1-3p & 6.987 & 0.036 & rno-miR-200c-5p & 2.622 & 0.022 \\
\hline rno-miR-205 & 6.898 & 0.004 & rno-miR-25-5p & 2.600 & 0.039 \\
\hline rno-miR-539-3p & 5.222 & 0.012 & rno-miR-505-5p & 2.497 & 0.040 \\
\hline rno-miR-878 & 4.879 & 0.037 & rno-miR-652-5p & 2.487 & 0.035 \\
\hline rno-miR-93-3p & 4.862 & 0.010 & rno-miR-376b-3p & 2.311 & 0.005 \\
\hline rno-miR-760-5p & 4.789 & 0.018 & rno-miR-410-5p & 2.278 & 0.019 \\
\hline rno-miR-3549 & 4.685 & 0.009 & rno-miR-23a-5p & 2.209 & 0.019 \\
\hline rno-miR-743b-5p & 4.681 & 0.034 & rno-miR-134-3p & 2.147 & 0.016 \\
\hline rno-miR-370-5p & 3.662 & 0.003 & rno-miR-299b-5p & 2.134 & 0.038 \\
\hline rno-miR-132-5p & 3.089 & 0.002 & rno-miR-204-3p & 2.125 & 0.019 \\
\hline \multicolumn{6}{|c|}{ Downregulated miRNAs in QSYQ low-dose versus ischemia model group } \\
\hline rno-miR-350 & 0.495 & 0.003 & rno-miR-142-3p & 0.300 & 0.000 \\
\hline rno-miR-338-5p & 0.490 & 0.002 & rno-miR-221-5p & 0.279 & 0.008 \\
\hline rno-miR-154-3p & 0.453 & 0.003 & rno-miR-1843-5p & 0.274 & 0.006 \\
\hline
\end{tabular}


TABLE 2: Continued.

\begin{tabular}{|c|c|c|c|c|c|}
\hline Gene & Fold change & $P$ value & Gene & Fold change & $P$ value \\
\hline rno-miR-532-5p & 0.435 & 0.002 & rno-miR-146a-5p & 0.265 & 0.000 \\
\hline rno-miR-336-5p & 0.425 & 0.005 & rno-miR-142-5p & 0.210 & 0.000 \\
\hline rno-miR-15b-5p & 0.417 & 0.006 & rno-miR-363-5p & 0.184 & 0.033 \\
\hline rno-miR-668 & 0.412 & 0.021 & rno-miR-1843-5p & 0.151 & 0.021 \\
\hline rno-miR-339-5p & 0.396 & 0.000 & rno-miR-223-3p & 0.117 & 0.000 \\
\hline rno-miR-380-5p & 0.374 & 0.031 & rno-miR-511-3p & 0.077 & 0.000 \\
\hline rno-miR-342-5p & 0.369 & 0.029 & rno-miR-346 & 0.074 & 0.018 \\
\hline rno-miR-674-3p & 0.313 & 0.001 & & & \\
\hline
\end{tabular}

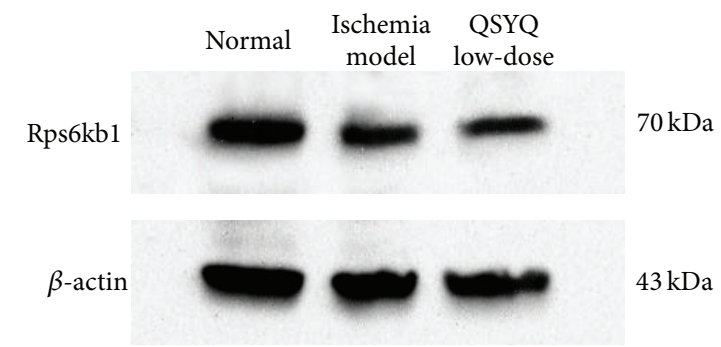

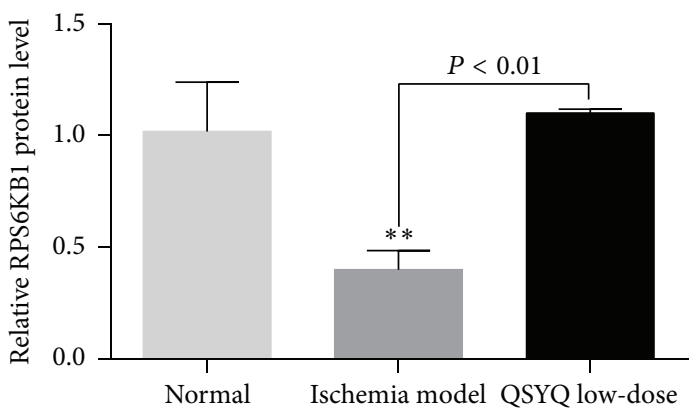

(a)

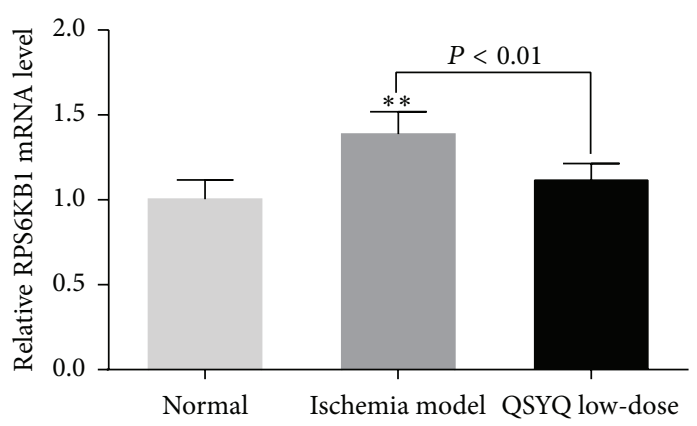

(b)

FiguRE 6: (a) Western-blot analyzed the protein level of RPS6KB1 in Q-L group and M group as compared to N group. It was showed that there was no significant difference in Q-L group and $\mathrm{N}$ group. $\beta$-actin was used as internal controls. ${ }^{* *} P<0.01$. (b) Real-time PCR analyzed the mRNA level of RPS6KB1 in Q-L group and M group as compared to N group. It was showed that there was no significant difference in Q-L group and $\mathrm{N}$ group. $\triangle \mathrm{Ct}$ values were normalized to GAPDH levels. ${ }^{* *} \mathrm{P}<0.01$.

downregulation of mir-223-3p in Q-L group $(P<0.01$, Figure 5(b)).

3.5. The mRNA and Protein Expression of Target Gene RPS6KB1. miRNAs play a role through regulating expression of target gene. It had been confirmed in previous study that $R$ ps $6 \mathrm{kb1}$ was the target gene of mir-223-3p in regulating angiogenesis of ischemic CMECs. The results of Rps6kb1 in western-blot analysis demonstrated that, compared with $\mathrm{N}$ group, there was significant downregulation in $\mathrm{M}$ group $(P=$ $0.001)$ and upregulation in Q-L group $(P=0.491)$; compared with $M$ group, there was significant upregulation in $\mathrm{Q}-\mathrm{L}$ group $(P=0.001$, Figure $6(\mathrm{a}))$. The results of mRNA expression of Rps6kb1 demonstrated that, compared with $\mathrm{N}$ group, there was significant upregulation in $\mathrm{M}$ group $(P=0.000)$ and upregulation in $\mathrm{Q}-\mathrm{L}$ group $(P=0.051)$; compared with $M$ group, there was significant downregulation in Q-L group $(P=0.000$, Figure $6(\mathrm{~b}))$. The segregation between mRNA and protein expression of target gene Rps $6 \mathrm{kbl}$ was consistent with the mechanism of miRNA negative regulation, while there was a significant improvement after QSYQ intervention.

3.6. QSYQ Promote Ischemic CMECs Angiogenesis by Regulating mir-223-3p Expression, Possibly Related to Upregulation of RPS6KB1/HIF-1 $\alpha$ Signaling Pathway. Previous research showed that HIF-1 $\alpha$ was an important transcription regulating factor for VEGF [15] and angiogenesis could be induced by upregulation of VEGF mRNA expression [16]. To further understand the mechanism of regulation of mir-2233 p expression by QSYQ in ischemic CMECs angiogenesis, we analyzed the signaling pathway of predicted RPS6KB1/HIF$1 \alpha$ and used real-time PCR and western-blot to test mRNA and protein expression, respectively, of related molecules in the signaling pathway: HIF- $1 \alpha$, VEGF, MAPK, PI3K, and AKT. Results showed that, compared with M group, mRNA and protein expression of the above-mentioned molecules 

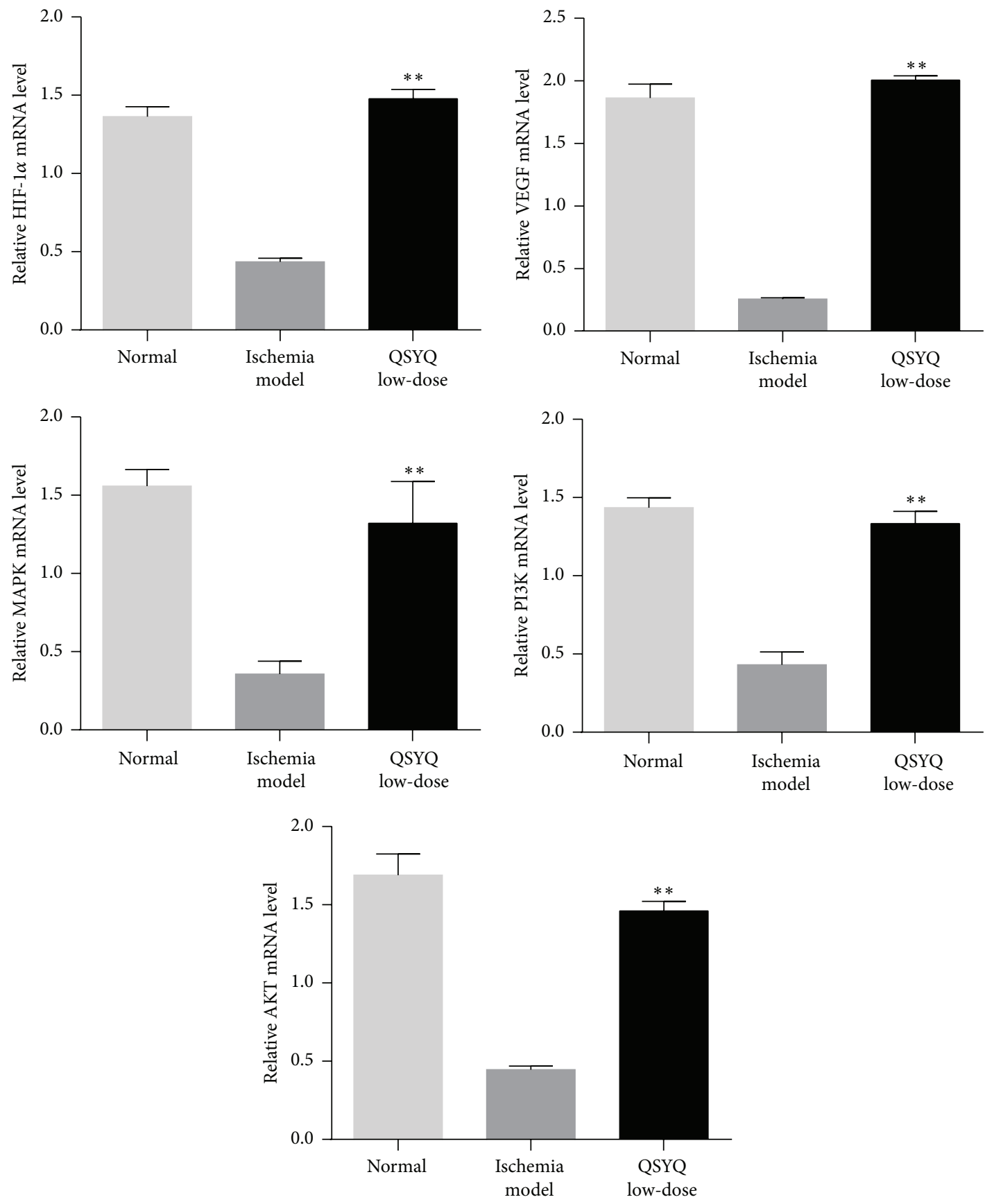

FIGURE 7: Real-time PCR analyzed the mRNA level of HIF-1 $\alpha$, VEGF, MAPK, PI3K, and AKT in Q-L group compared with M group. ${ }^{* *} P<$ 0.01 .

in the Q-L group were significantly elevated $(P<0.01$ or $P<0.05$, Figures 7 and 8 ), suggesting that QSYQ induced expression of related molecules on the RPS6KB1/HIF- $1 \alpha$ signaling pathway via downregulating mir-223-3p expression during CMECs angiogenesis and thereby promoted ischemic cardiac angiogenesis.

\section{Discussions}

Previous research showed that QSYQ can elevate mRNA and protein expression of VEGF and basic fibroblast growth factor, promote angiogenesis, increase blood supply in ischemic areas, reduce myocardial infarction area, and function to combat cardiac ischemia [17]. Previous studies also showed that miRNAs are closely associated with angiogenesis and they promote/inhibit angiogenesis by regulating target gene expression $[18,19]$. However, there is no detailed report to date on the regulation of miRNAs by QSYQ.

The previous experiment results showed that mir-223$3 \mathrm{p}$ was a direct target of rats ischemic CMECs angiogenesis, decreased expression of VEGF, MAPK, PI3K, and so forth, inhibited proliferation and migration of ischemic CMECs, 

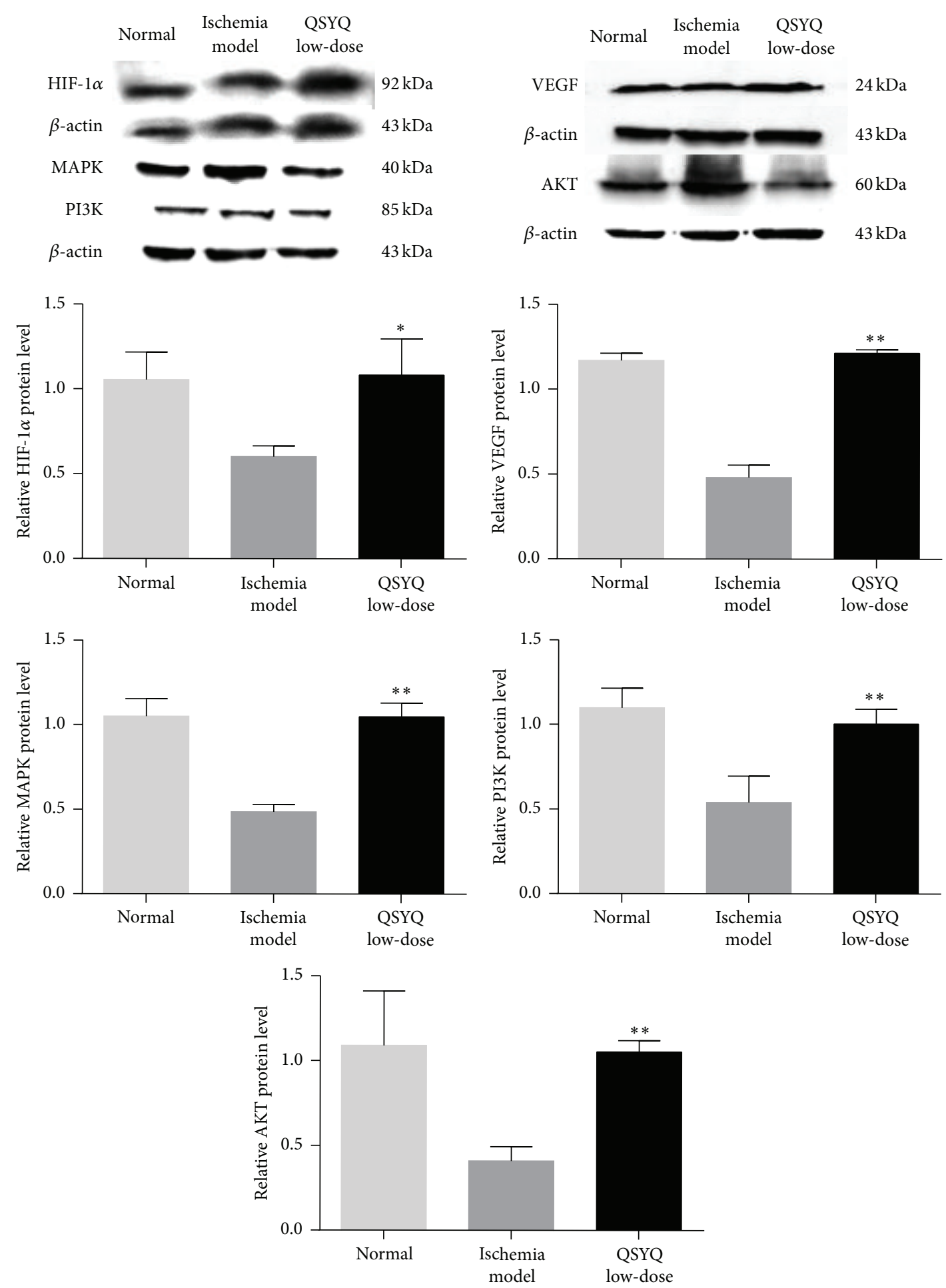

FIGURE 8: Western-blot analyzed the protein level of HIF-1 $\alpha$, VEGF, MAPK, PI3K, and AKT in Q-L group compared with M group. $\beta$-actin was used as internal controls. ${ }^{*} P<0.05,{ }^{* *} P<0.01$.

via affecting RPS6KB1/HIF-1 $\alpha$ signal pathway, and thereby suppressed angiogenesis of ischemic myocardium. Based on previous study and the results, this study figured out the optimum dosage and window period for QSYQ for the regulation of ischemic CMECs angiogenesis. The present study confirmed that QSYQ could promote the angiogenesis of ischemic myocardium, though it did not demonstrate a dosedependent style. The results indicated that the proliferation window period of ischemic CMECs in Q-L group was four days ahead of that of the $\mathrm{M}$ group and the migration and 
tube formation rate of Q-L group were significantly higher than other groups $(P=0.000)$, which suggested that $\mathrm{Q}-\mathrm{L}$ group and proliferation period were the optimum dosage and window period for QSYQ intervening in ischemic CMECs angiogenesis. To further explore the function target and mechanisms of QSYQ in the regulation of ischemic CMECs angiogenesis based on miRNA, we used the optimum dosage and window period of QSYQ as the intervention group, used gene chip to analyze the miRNA active expression changes from intervention group, $\mathrm{M}$ group, and $\mathrm{N}$ group, and found that expression of mir-223-3p in intervention group was downregulated 0.117 times as much as $\mathrm{M}$ group, denoting a very significant difference. Real-time PCR analysis on mir223-3p agreed with chip results. After comprehensive analysis, we confirmed mir-223-3p as the core miRNA from QSYQ in regulating ischemic CMECs angiogenesis. The results of mRNA and protein expression of $R p s 6 k b 1$ as the target of mir223-3p demonstrated the segregation phenomenon between them, which was consistent with the mechanism of miRNA negative regulation. Following that, we found that there was an obvious improvement after QSYQ intervention.

The miRNAs function through regulating target gene expressions. To further discuss the mechanism of the regulation on mir-223-3p after the intervention from QSYQ, we tested related molecules HIF-1 $\alpha$, VEGF, MAPK, PI3K, and AKT with real-time PCR and western-blot. Results showed significant upregulation from the mRNA and protein expressions of the above-mentioned molecules. VEGF, an important regulator of angiogenesis, which is usually induced to upregulate by hypoxia and ischemia, promotes angiogenesis [20]. MAPK can activate a variety of transcription factors, promotes gene expression, and further promotes cell proliferation and differentiation. PI3K is a core signaling molecule of human life activities, and the mediated signal transduction pathway can regulate cell proliferation, differentiation, apoptosis, and other processes [21, 22]. AKT, a key factor for cell survival, plays an important role in antiapoptosis, cell survival, and proliferation. A number of studies indicate that many growth factors induced by hypoxia can increase the proliferation of vascular smooth muscle cells via PI3K/AKT signaling pathway, and MAPK, as a target molecule of PI3K downstream, can regulate cell proliferation by PI3K/MAPK signaling pathway. In conclusion, the study suggests that QSYQ can promote angiogenesis by downregulating mir223-3p expressions and elevating expressions of factors on the RPS6KB1/HIF-1 $\alpha$ signaling pathway, including VEGF, MAPK, and PI3K.

QSYQ are the main representative of Qi-replenishing and blood-activating TCM to treat ischemic heart disease, with several positive treatment features. Research shows that all components of QSYQ promote angiogenesis and improve cardiac ischemia [23-26]. Astragaloside IV, one of the main components from Astragalus, promotes angiogenesis primarily through activating PI3K/AKT signaling pathway and promoting HIF- $1 \alpha$ protein synthesis, thereby elevating VEGF mRNA levels [23]; the main component from red sage, tanshinone IIA, can elevate expressions of VEGF through increasing HIF-1 $\alpha$ mRNA expressions [24], and red sage plus its various extracts can all promote angiogenesis, reduce myocardial infarction area, and improve heart functions; the effective component from Panax notoginseng, notoginsenoside, can promote angiogenesis via VEGF-KDR/FLK1 pathway and PI3K-AKT-eNOS signaling pathway [25]; and Dalbergia odorifera has anticardiac ischemia functions as well [26]. The multitarget and multipathway regulation characteristics of TCM components function well in various treatment modalities. Therefore, new ideas for TCM and miRNA research have been provided from discussion of the link between QSYQ and miRNAs.

Our study found via gene chip analysis that QSYQ can regulate multiple miRNA expression and intervention with ischemic CMECs angiogenesis. Among these, mir223-3p showed the most significant expression changes, suggesting that QSYQ promote ischemic cardiac angiogenesis through regulating mir-223-3p expressions, which also involves upregulation of RPS6KB1/HIF- $1 \alpha$ signaling pathway, and these have provided experimental evidence for research on miRNA array analysis of ischemic CMECs and drug intervention. Nonetheless, our current results are only limited to experimental research, more rigorous, and thorough clinical studies are needed in the future to provide more robust theoretical evidence for TCM in treating ischemic heart disease.

\section{Conflict of Interests}

The authors report no conflict of interests.

\section{Acknowledgment}

The authors are grateful for the assistance of the National Natural Science Foundation of China (NSFC: 81173441).

\section{References}

[1] G.-H. Dai, "The research methods in TCM of ischemia myocardium angiogenesis of coronary heart disease," Journal of Shandong University of Traditional Chinese Medicine, vol. 26, no. 6, pp. 417-419, 2002.

[2] D. P. Bartel, "MicroRNAs: genomics, biogenesis, mechanism, and function," Cell, vol. 116, no. 2, pp. 281-297, 2004.

[3] G.-H. Dai, P.-Z. Ma, X.-B. Song, N. Liu, T. Zhang, and B. Wu, "MicroRNA-223-3p inhibits the angiogenesis of ischemic cardiac microvascular endothelial cells via affecting RPS6KB1/hifla signal pathway," PLoS ONE, vol. 9, no. 10, Article ID e108468, 2014.

[4] Q.-B. Song, Z.-Y. Che, and Y. Zou, "Rat blood collection methods," Journal of Clinical Rehabilitative Tissue Engineering Research, vol. 12, no. 50, pp. 9990-9992, 2008.

[5] H. Drexler, J. W. Depenbusch, A. G. Truog, R. Zelis, and S. F. Flaim, "Effects of diltiazem on cardiac function and regional blood flow at rest and during exercise in a conscious rat preparation of chronic heart failure (myocardial infarction)," Circulation, vol. 71, no. 6, pp. 1262-1270, 1985.

[6] J.-I. Sadoshima, L. Jahn, T. Takahashi, T. J. Kulik, and S. Izumo, "Molecular characterization of the stretch-induced adaptation of cultured cardiac cells. An in vitro model of load-induced cardiac hypertrophy," The Journal of Biological Chemistry, vol. 267, no. 15, pp. 10551-10560, 1992. 
[7] S. Xian-Bo, M. Pei-Ze, G. Wei et al., "Culture and identification of ischemic cardiac microvascular endothelial cells in the rats," World Journal of Integrated Traditional and Western Medicine, vol. 8, no. 12, pp. 1215-1246, 2013.

[8] J. A. Manthey and N. Guthrie, "Antiproliferative activities of citrus flavonoids against six human cancer cell lines," Journal of Agricultural and Food Chemistry, vol. 50, no. 21, pp. 5837-5843, 2002.

[9] Y. J. Hwang, S. M. Park, C. B. Yim, and C. Im, "Cytotoxic activity and quantitative structure activity relationships of arylpropyl sulfonamides," Korean Journal of Physiology and Pharmacology, vol. 17, no. 3, pp. 237-243, 2013.

[10] J. C. Lim, S. Y. Park, Y. Nam, T. T. Nguyen, and U. D. Sohn, "The protective effect of eupatilin against hydrogen peroxideinduced injury involving 5-lipoxygenase in feline esophageal epithelial cells," Korean Journal of Physiology and Pharmacology, vol. 16, no. 5, pp. 313-320, 2012

[11] S. Y. Park and U. D. Sohn, "Inhibitory effect of rosiglitazone on the acid-induced intracellular generation of hydrogen peroxide in cultured feline esophageal epithelial cells," NaunynSchmiedeberg's Archives of Pharmacology, vol. 383, no. 2, pp. 191201, 2011.

[12] G. Cory, "Scratch-wound assay," Methods in Molecular Biology, vol. 769, pp. 25-30, 2011.

[13] Z. K. Yuan, L. Mo, X. P. Huang et al., "The impact of the effective components recipe of YangXinTongMai formula on the angiogenesis of rat endothelium," Progress in Modern Biomedicine, vol. 9, no. 8, pp. 1405-1408, 2009.

[14] R. W. Kass, M. N. Kotler, and S. Yazdanfar, "Stimulation of coronary collateral growth: current developments in angiogenesis and future clinical applications," American Heart Journal, vol. 123, no. 2, pp. 486-496, 1992.

[15] G.-H. Fong, "Mechanisms of adaptive angiogenesis to tissue hypoxia," Angiogenesis, vol. 11, no. 2, pp. 121-140, 2008.

[16] Y. Liu, S. R. Cox, T. Morita, and S. Kourembanas, "Hypoxia regulates vascular endothelial growth factor gene expression in endothelial cells. Identification of a $5^{\prime}$ enhancer," Circulation Research, vol. 77, no. 3, pp. 638-643, 1995.

[17] L. Zhang, Y. Wang, L. Yu et al., "QI-SHEN-YI-QI accelerates angiogenesis after myocardial infarction in rats," International Journal of Cardiology, vol. 143, no. 1, pp. 105-109, 2010.

[18] J. E. Fish, M. M. Santoro, S. U. Morton et al., "miR-126 regulates angiogenic signaling and vascular integrity," Developmental Cell, vol. 15, no. 2, pp. 272-284, 2008.

[19] L. Poliseno, A. Tuccoli, L. Mariani et al., "MicroRNAs modulate the angiogenic properties of HUVECs," Blood, vol. 108, no. 9, pp. 3068-3071, 2006.

[20] Y. Y. Cai and G. Z. Li, "Advances in the regulation and role of VEGF," Journal of Tissue Engineering and Reconstructive Surgery, vol. 7, no. 1, pp. 51-54, 2011.

[21] I. Shiojima and K. Walsh, "Role of Akt signaling in vascular homeostasis and angiogenesis," Circulation Research, vol. 90, no. 12, pp. 1243-1250, 2002.

[22] D. W. Losordo and S. Dimmeler, "Therapeutic angiogenesis and vasculogenesis for ischemic disease: part I: angiogenic cytokines," Circulation, vol. 109, no. 21, pp. 2487-2491, 2004.

[23] L. Zhang, Q. Liu, L. Lu, X. Zhao, X. Gao, and Y. Wang, "Astragaloside IV stimulates angiogenesis and increases hypoxiainducible factor- $1 \alpha$ accumulation via phosphatidylinositol 3kinase/akt pathway," Journal of Pharmacology and Experimental Therapeutics, vol. 338, no. 2, pp. 485-491, 2011.
[24] X. We, Y. Jun, and L. M. Wu, "Cardioprotective effects of tanshinone IIA on myocardial ischemia injury in rats," Die Pharmazie, vol. 64, no. 5, pp. 332-336, 2009.

[25] S.-J. Hong, J.-B. Wan, Y. Zhang et al., "Angiogenic effect of saponin extract from Panax notoginseng on HUVECs in vitro and zebrafish in vivo," Phytotherapy Research, vol. 23, no. 5, pp. 677-686, 2009.

[26] Z. Qian, G. Jixian, and Z. Yunyi, "Chemical and pharmacological research progress of Chinese drug "JiangXiang" (lignum dalbergiae odoriferae)," Journal of Chinese Pharmaceutical Sciences, vol. 9, no. 1, pp. 1-5, 2000. 


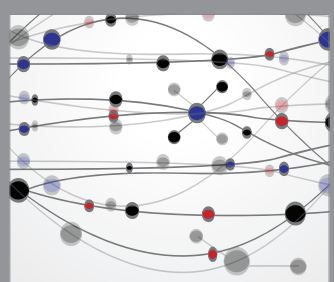

The Scientific World Journal
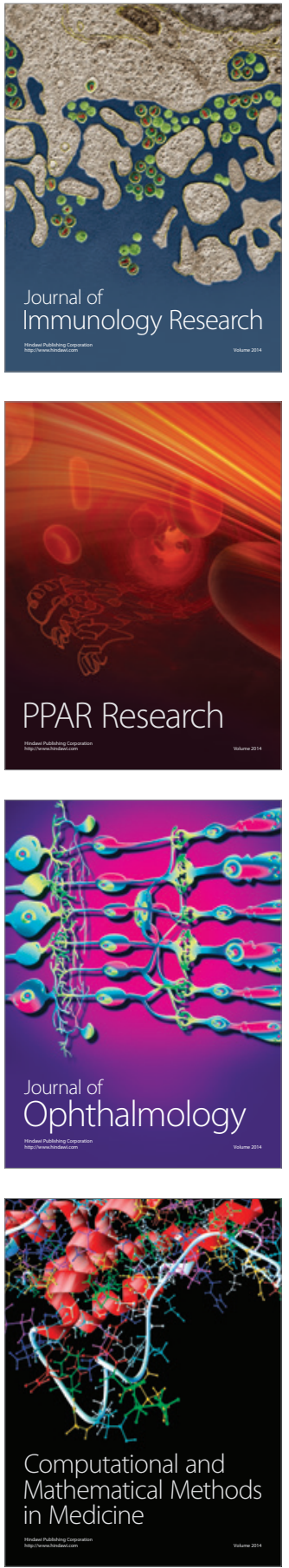

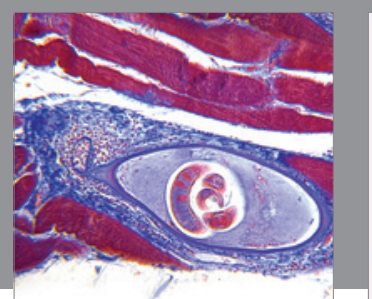

Gastroenterology Research and Practice

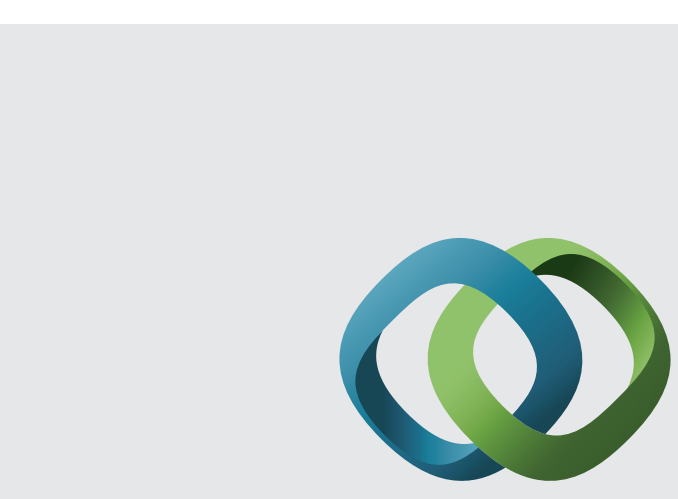

\section{Hindawi}

Submit your manuscripts at

http://www.hindawi.com
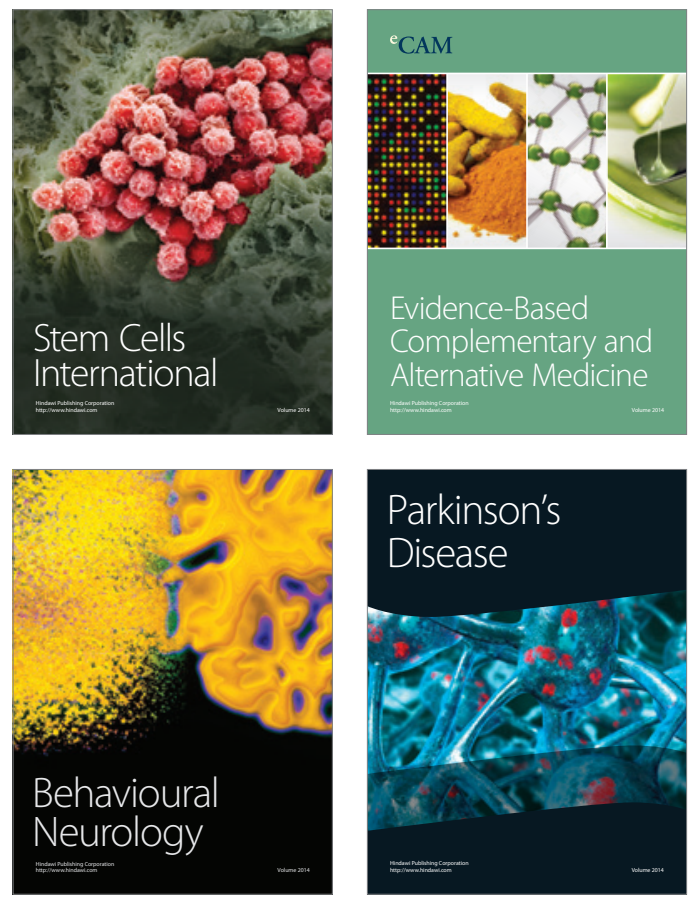
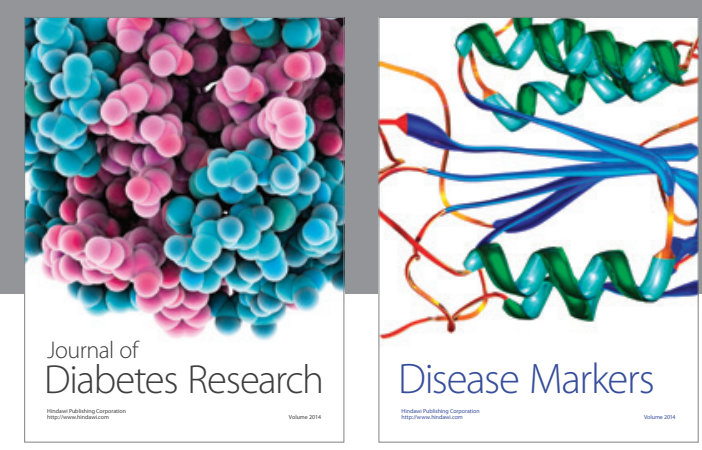

Disease Markers
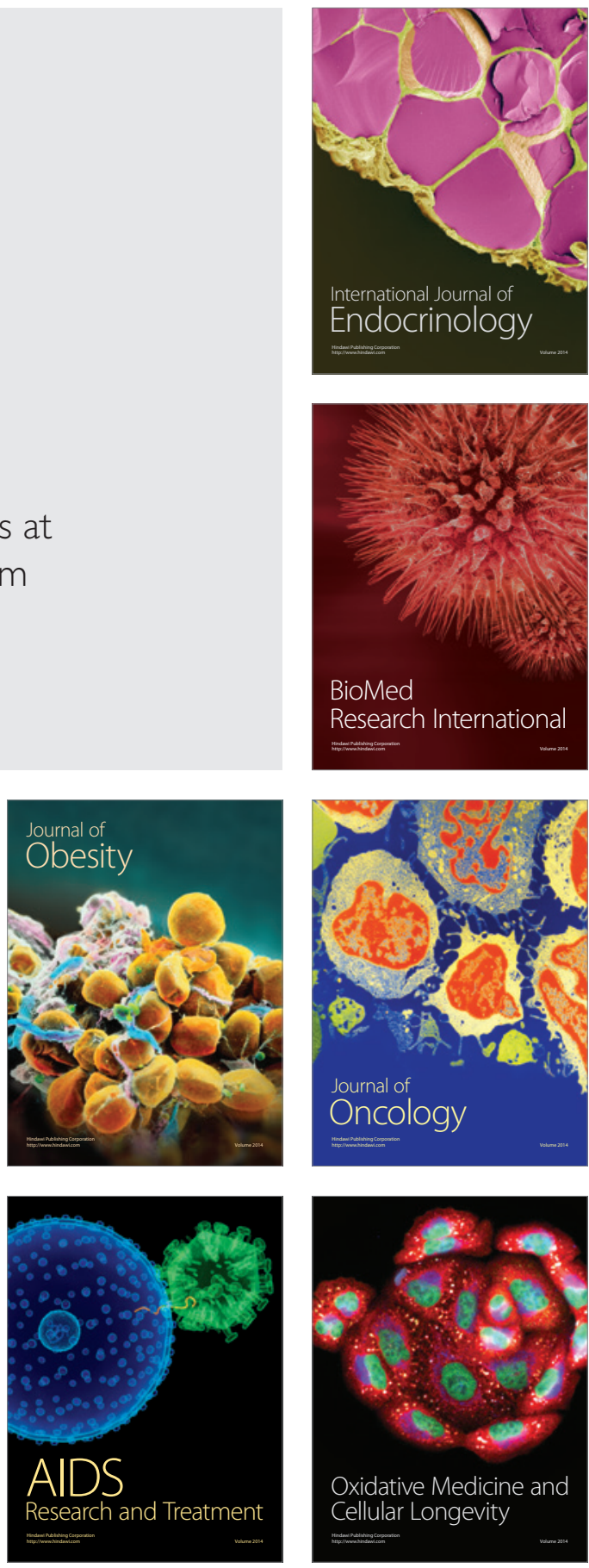